\title{
Interférences
}

Ars scribendi

\section{Retrato y biografía en el libro I de Tito Livio}

\author{
Jorge Martínez-Pinna
}

\section{OpenEdition}

Journals

Edición electrónica

URL: http://journals.openedition.org/interferences/942

DOI: 10.4000/interferences.942

ISSN: $1777-5485$

Editor

HiSoMA - Histoire et sources des Mondes antiques

Edición impresa

Fecha de publicación: 1 enero 2009

ISSN: 1777-5485

\section{Referencia electrónica}

Jorge Martínez-Pinna, « Retrato y biografía en el libro I de Tito Livio », Interférences [En ligne], 5 | 2009, mis en ligne le 11 décembre 2014, consulté le 15 septembre 2020. URL : http://

journals.openedition.org/interferences/942 ; DOI : https://doi.org/10.4000/interferences.942

Este documento fue generado automáticamente el 15 septiembre 2020.

Tous droits réservés 


\title{
Retrato y biografía en el libro I de Tito Livio
}

\author{
Jorge Martínez-Pinna
}

1 Cuando nos referimos a los antiguos relatos sobre la época monárquica de Roma, utilizamos el término de analística, y verdaderamente debe ser así, ya que en su inmensa mayoría la historiografía republicana organizaba sus contenidos mediante un esquema anual ${ }^{*}$. Pero este sistema exige un esqueleto cronográfico acorde, que sólo existió a partir de la República gracias a la datación consular, no con anterioridad. Las indicaciones cronológicas relativas a la lejana época de los reyes, salvo la duración de los diferentes reinados, son escasísimas y, por lo demás, sólo obedecen a meras especulaciones sin fundamento alguno ${ }^{1}$. Por ello, stricto sensu quizás no debería aplicarse este calificativo de "analística" a la historiografía sobre la era monárquica, aunque como se sabe el término annales significaba asimismo la redacción de la historia pasada $^{2}$. Como es lógico, para la época más antigua, los acontecimientos no son narrados por años, sino por reinados ${ }^{3}$. Habría que preguntarse entonces si el libro I de Tito Livio no es en realidad sino una sucesión de biografías, cuyos protagonistas serían los mismos reyes.

2 En el prefacio de su obra, Livio resalta el carácter instructivo de la historia, en cuanto que conserva el recuerdo y la esencia de las virtudes tradicionales. Pero tales virtudes no quedan relegadas a una simple abstracción, sino que se materializan en los grandes personajes de la historia romana, aquellos que gracias a sus valores y formación, elevaron a Roma a una posición de supremacía mundial ${ }^{4}$. Es por tanto a través de la evocación de la personalidad y la obra de tales individuos como la historia puede cumplir esta función educadora. Una perspectiva biográfica parece pues que se encuentra implícita en el objetivo de la narración histórica de Livio. Aun así, surge la duda si en realidad existe un propósito histórico-biográfico, o si por el contrario prima tan sólo la intención por describir retratos. En otras palabras, si se refleja más en los criterios fijados por la escuela alejandrina, es decir una narración científica de la vida del personaje, desde su nacimiento hasta su muerte, o bien, conforme a la más antigua tendencia peripatética, centra preferentemente la atención en el carácter y virtudes 
morales del protagonista ${ }^{5}$. Como dice Cornelio Nepote en referencia a Pelópidas, la historia relata hechos, res, la biografía transmite virtutes ${ }^{6}$.

3 No hay duda de que el retrato, así entendido, tiene en la obra de Livio una presencia bastante intensa ${ }^{7}$. Así lo afirmaba ya $\mathrm{H}$. Taine, según el cual «le plus beau de ces portraits est celui du peuple romain ${ }^{8}$, en el sentido de que los diferentes protagonistas, sobre todo a través de sus discursos, personifican las virtudes del pueblo romano. Estos retratos se encuentran insertos a lo largo de toda la narración, siendo los más notables por su extensión, como recientemente ha mostrado J.-E. Bernard, los relativos a Catón, Aníbal y Papirio Cursor ${ }^{9}$. Pero también los reyes atrajeron en este aspecto el interés de Livio.

4 Al tratar sobre el carácter de los diferentes reyes, Livio no elige siempre el mismo lugar. Con razón sugiere Bernard que la ocasión de la muerte del personaje es momento propicio para trazar algunos rasgos esenciales de su personalidad y hacer balance de su obra $^{10}$. Así sucede respecto a los reyes, pero no con todos. Verdaderamente sólo en los relatos de Rómulo y Servio Tulio se constata este hecho. Sobre Rómulo, afirma Livio la creencia en su nacimiento divino ${ }^{11}$, su valor, su sabiduría, su vocación popular, virtudes que en definitiva le valen adquirir una naturaleza divina ${ }^{12}$. Respecto a Servio, si bien al narrar su infancia resalta su condición superior, pues ya posee cualidades innatas propias para desempeñar la realeza, es en el momento de la muerte cuando dibuja un retrato más completo sobre su carácter: en opinión de Livio, Servio era una persona llena de virtud y de sabiduría, que ejerció una autoridad dulce y moderada, otorgándole en última instancia una proyección republicana ${ }^{13}$. La situación no es exactamente la misma respecto a los otros reyes.

5 La muerte de Numa Pompilio, de Tulo Hostilio y de Anco Marcio sólo suscita en Livio la necesidad de una indicación cronológica, los años de los respectivos reinados, y una brevísima referencia a la grandeza de sus obras ${ }^{14}$. Los retratos de estos tres reyes se encuentran en el inicio de sus reinados. El de Numa es descrito a propósito de la supuesta relación entre el rey y el filósofo Pitágoras, que Livio rechaza por problemas cronológicos e ideológicos ${ }^{15}$, pero que no obstante le sirve para presentar el carácter de Numa, que se distinguía por la equidad, la piedad y la austeridad, así como por un profundo conocimiento del derecho divino y humano; sus virtudes derivan en definitiva del mismo carácter del pueblo sabino al cual pertenecía, y de ahí la falsa creencia de que Numa había sido discípulo de Pitágoras ${ }^{16}$. El retrato de Tulo es más breve y destaca fundamentalmente la naturaleza belicosa del monarca: ferocior etiam quam Romulus fuit ${ }^{17}$. El juicio de Livio sobre Tulo es en general negativo, como se aprecia muy bien en los preámbulos de la guerra contra Alba, cuya responsabilidad es atribuida al rey de Roma, en contra de lo que figura en Dionisio, Diodoro y posiblemente Cicerón ${ }^{18}$; o en el castigo que infligió a Mettio Fufetio, de tal crueldad que iba en contra de las leyes de la humanidad ${ }^{19}$; de similar manera se observa cuando en las postrimerías de su reinado, Tulo decidió dulcificar su carácter acudiendo a las prácticas religiosas, hasta entonces abandonadas, pero tal actitud es calificada como superstitio ${ }^{20}$. Sin embargo, a propósito del proceso contra Horacio por la muerte de su hermana, Livio adopta hacia Tulo una posición más benigna, según se trasluce de las palabras clemente legis interprete $e^{21}$. Esta contradicción por parte de Livio, unida a otras presentes en su relato sobre el reinado de Tulo, sólo se justifica admitiendo la utilización de dos fuentes diferentes ${ }^{22}$. Por último, el retrato de Anco es asimismo muy conciso: el carácter de este 
monarca se sitúa entre el de Rómulo y el de Numa, si bien las circunstancias del momento exigían más a un Tulo que a un $\mathrm{Numa}^{23}$.

6 Con los Tarquinios se observa un planteamiento diferente. De ninguno de ellos Livio describe un auténtico retrato, al estilo de los anteriores. Sobre Tarquinio Prisco pesa la condición de ser el primer monarca verdaderamente extranjero, en el sentido de que con él se introducen en Roma costumbres que no se identifican con los valores tradicionales. Como se verá más adelante, Tarquinio Prisco personifica la ambitio, y la utilización que hace de sus bienes se opone al concepto de frugalitas, virtud fundamental de la moralidad romana, ya que este rey fue quien introdujo la riqueza como instrumento de promoción política. Pero además existe la percepción, si bien no claramente expresada en el texto tradicional, de que a partir de estos momentos el devenir histórico de Roma experimenta un notable cambio. Aunque Livio invoca los antecedentes de Tito Tacio y sobre todo de Numa como justificación de la llegada al poder de un extranjero, en realidad la situación no es la misma. Numa fue requerido para ocupar el trono y buscado en su lugar de origen; por el contrario, Tarquinio ya habitaba en Roma y él mismo se postuló para la realeza al estilo de los políticos de la República. Aun así su inserción en la lista real exigía una explicación, y de ahí el extenso tratamiento que Livio, al igual que los otros analistas, concede al origen de este personaje, con las historias de Demarato y de Lucumo, y la necesidad de al menos un prodigio que avalase su predestinación a la realeza, lo que se cumplió en el episodio del águila en el Janículo. El retrato que presenta Livio de Tarquinio Prisco es muy diferente en su contenido al que aplica a los otros reyes. En él no se describe propiamente el carácter del protagonista, sino que justifica su pretensión a la realeza por haber asumido las virtudes tradicionales del ciudadano romano ${ }^{24}$. Naturalmente no oculta que Tarquinio posee cualidades (pero sin especificar cuáles) y una especial devoción hacia la ciudad, lo que le convierte en un monarca beneficioso para Roma.

El caso de Tarquinio el Soberbio no deja de sorprender. Teniendo en cuenta que este personaje representa como ningún otro el tipo del tirano, en la exposición de su reinado que hace Livio no incluye un verdadero retrato. En el momento de ser expulsado del trono, Livio aprovecha para ofrecer el dato de los años del reinado de Tarquinio, y cuando menciona su muerte, sucedida en el exilio de Cumas años después, no hace comentario alguno sobre la figura del depuesto monarca, sino tan sólo acerca de la impresión que causó en Roma el conocimiento de este hecho ${ }^{25}$. La personalidad moral de Tarquinio sólo se aprecia a través de leves pinceladas, como cuando Livio compara el carácter dulce de su hermano Arrunte con la violencia que embarga a Tulia Maior y al propio Tarquinio (mite ingenium / ingenia violenta) ${ }^{26}$, o cuando afirma que si Tarquinio era injusto en tiempos de paz, no carecía de virtudes para la guerra, en lo que podemos considerar como lo más próximo a un retrato ${ }^{27}$. Su verdadero carácter aparece reflejado sobre todo en sus hechos.

8 Sin embargo, Livio no pierde la ocasión de trazar un breve retrato de la perversa reina Tulia, cuyo carácter es descrito en concisas y duras palabras: ferox, cupiditas, audacia son los términos que señalan a esta mujer ${ }^{28}$. Resulta evidente el contraste con Lucrecia, la gran protagonista femenina del relato tradicional sobre el final de la monarquía. Su carácter se trasluce asimismo en sus hechos, en su comportamiento, en su actitud. Lucrecia encarna la pudicitia, una de las virtudes más ensalzadas por Livio como patrimonio de la moral tradicional ${ }^{29}$. La presentación del personaje no puede ser más clarificadora: frente a la vida in convivio luxuque que permanentemente disfrutan las 
nueras de Tarquinio, Lucrecia pasa las veladas trabajando la lana ayudada por sus esclavas $^{30}$. No se trata sólo de confrontar el modo de vida de la mujer etrusca, practicado por las esposas de los Tarquinios ${ }^{31}$, con las costumbres romanas, sino que en cierto sentido Lucrecia, posesora de las virtudes que compendian el prototipo de la tradicional matrona romana, representa a la República, que surgirá de su sangre, mientras que sus oponentes reflejan la decadente monarquía.

En opinión de E. Burck, en la primera década de Livio no se describen figuras concretas, individuales, sino en todo caso tipos de antiguos romanos ${ }^{32}$. Esta misma línea es desarrollada por Bernard a propósito de los reyes, estableciendo finalmente cinco aspectos en torno a los cuales giran las personalidades de los diferentes monarcas: rey justo y legítimo, rey tiránico, rey guerrero, rey religioso, rey edificador ${ }^{33}$. En no escasa medida estas características personales se ajustan también a las condiciones de la época. Si exceptuamos las dos primeras, las restantes representan las funciones más relevantes de la realeza: la guerra, la dirección de la religión pública y el desarrollo urbanístico de Roma. En mayor o menor grado, casi todos los reyes de Roma participan de estas características, aunque no es menos cierto que algunos de ellos destacaron especialmente en determinadas actividades. Tal es el caso de Numa y de Tulo, según acabamos de ver, que personalizan en la tradición las funciones religiosa y guerrera respectivamente, si bien las fuentes no dejan de mencionar algunas iniciativas de Tulo en el ámbito de la religión. Un caso singular es el de Numa, rey pacífico por excelencia que consagró toda su actividad política a la organización de la vida religiosa. Pero en realidad no podía ser de otra manera, ya que Numa es el complemento necesario del fundador ${ }^{34}$. Además su célebre nomothesía sacerdotal, sobre todo como se puede leer en la exposición que de la misma hace Dionisio, esconde en el fondo una fuerte motivación política al estar implicadas, desde una perspectiva religiosa, las instituciones existentes en la primera $\mathrm{Roma}^{35}$. Un caso similar es el de Servio, prototipo de rey legislador pero que, al contrario de Numa, también sobresalió en la guerra, si bien la tradición tan sólo menciona una campaña emprendida por este monarca ${ }^{36}$. Precisamente la función legisladora es otra de las que caracteriza la personalidad de los reyes, ya que todos ellos, excepto Tarquinio el Soberbio, llevan a cabo alguna actividad en este campo. Pero se trata igualmente de una función necesaria en el proceso de definición institucional de Roma, en el cual cada uno de los monarcas interpreta su papel, al igual que en los otros aspectos "fundacionales".

Tan sólo Tarquinio el Soberbio se mantiene en parte al margen de estas características, consecuencia de la oposición, señalada por Bernard, entre rey justo y legítimo, por un lado, y rey tiránico, por otro. La antigua tradición imaginaba la historia de la monarquía romana como una línea ascendente, con su origen en Rómulo y la propia fundación de la ciudad y el punto culminante en Servio Tulio ${ }^{37}$, para a continuación caer bruscamente con el reinado del último Tarquinio. Los seis primeros reyes eran legítimos, y no en vano el mismo Livio, en el prefacio del libro II, les califica con el término de conditores, ya que con su obra contribuyeron al desarrollo y prosperidad de Roma $^{38}$. En la cúspide de la serie se encuentra Servio, de quien dice Livio que fue el último rey justo y legítimo ${ }^{39}$, a pesar de que su acceso al trono se produjo de manera por completo irregular, ya que Servio, según palabras del propio Livio, primus iniussu populi, voluntate patrum regnavit $t^{40}$. Esta contradicción entre la legitimidad de su realeza y una entronización anómala desde el punto de vista constitucional, se justifica por otra paradoja: Servio personifica el cénit de la monarquía por ser precisamente el primer republicano. Y en efecto, Livio no pierde ocasión para resaltar este "republicanismo" de 
Servio. Así, se hace portavoz de aquella variante de la tradición según la cual Servio pretendía dimitir como rey e instaurar la libertas, es decir la República ${ }^{41}$, y la misma impresión se siente al leer la frase que cierra el libro I, cuando Livio afirma que los primeros cónsules fueron elegidos ex commentariis Ser. Tullii42 .

11 Como podemos observar, en el texto de Livio sobre la época arcaica existe un vínculo directo entre Servio y la República, de manera que esta última viene a ser "hija" del primero. En medio se sitúa Tarquinio el Soberbio, quien por fuerza asume en su persona todas las connotaciones negativas de la monarquía. No cabe duda de que la realeza de Tarquinio fue más absoluta que la de sus inmediatos predecesores, e incluso despótica, y que la tradición la transformó en una tiranía. Este concepto político griego llegó a Roma a mediados del siglo III a.C. mediante la adaptación de tragedias griegas que giraban en torno a este motivo ${ }^{43}$, y ya el poeta Accio, en su praetexta titulada Brutus y centrada en los orígenes de la República, hablaba de Servio Tulio como inspirador del nuevo régimen ${ }^{44}$ y presentaba a Tarquinio como encarnación de la más pura tiranía ${ }^{45}$. A esta forma "trágica" de la figura del tirano se une en el siglo i a.C. el tipo "retórico", motivo muy utilizado en las controversias políticas de finales de la República y que incide con fuerza en la caracterización histórica de Tarquinio.

Livio recoge este bagaje literario e ideológico y lo aplica sistemáticamente a Tarquinio y a otros miembros de su familia, especialmente su hijo Sexto. Conceptos como crudelitas, superbia, vis, libido, que con frecuencia eran utilizados en el lenguaje de la diatriba política como propios de quien aspira a un poder personal, o de quien se comporta de manera arbitraria y contra natura, son asimismo usados para caracterizar la figura de Tarquinio ${ }^{46}$. Pero tales apelativos rebasan el ámbito meramente personal, la descripción del retrato de un rey tiránico, para entrar de lleno en una valoración político-moral que contrapone la monarquía y la República. Según palabras de P.Zancan, en el pensamiento de Livio «la libertas è diventata l'emblema della repubblica e la superbia del regnum $»^{47}$, y en efecto, regnum y libertas significan dos ideas antitéticas. Tarquinio, llamado en consecuencia Superbus, personifica el odium regni y atrae hacia sí toda la aversión que los romanos sentían hacia el régimen monárquico: el Tarquiniorum nomen acaba, en la visión de Livio, representando un verdadero peligro para la libertas ${ }^{48}$.

No todos los reyes son considerados por Livio bajo este mismo aspecto negativo, como antes veíamos. Pero Livio parece sentir en general escasa simpatía hacia el régimen monárquico, según se deduce de las palabras que utiliza cuando tras la muerte de Rómulo, el Senado decide, a pesar de las diferencias surgidas en su seno, que Roma debe continuar bajo el gobierno de un rey ${ }^{49}$. En su opinión, la monarquía es una fase necesaria en la historia de Roma, como preparación para la llegada de la República ${ }^{50}$. De ahí también la necesidad de incrementar los aspectos "tiránicos" de la personalidad de Tarquinio y de su reinado, ya que su actitud cruel y violenta, contraria al espíritu de la monarquía tradicional, exigía el cambio de régimen en una sociedad ya modernizada con las reformas de Servio ${ }^{51}$.

14 En los retratos de los reyes que ofrece Livio, Numa representa la pietas, Tulo la ferocitas, Anco se sitúa entre ambos, Tarquinio Prisco personifica la ambitio, Servio Tulio la moderatio y finalmente el último Tarquinio la superbia. En términos generales, esta caracterización de los reyes es producto de la tradición, si bien Livio, como subraya P.G. Walsh, «is content to lend renewed emphasis to the moral excellences or defects for which these idividuals were well known» ${ }^{52}$. Pero no sólo. Livio propone asimismo desarrollos propios que pueden llegar a definir una visión original del personaje. Así 
puede observarse a propósito de Tarquinio Prisco, sobre el cual Livio no ofrece un retrato completo, pero sí destaca como aspecto más sobresaliente de su personalidad la ambición política ${ }^{53}$.

Ya desde la misma presentación del personaje, cuando Tarquinio era todavía Lucumo, destaca Livio su ambición por alcanzar grandes honores que su patria, la etrusca Tarquinia, le negaba, objetivo en el que fue empujado por su esposa Tanaquil, embargada por idénticos deseos ${ }^{54}$. En este capítulo Livio emplea el término cupido, que aplicado al ámbito del poder, aparece asimismo en ocasiones anteriores ${ }^{55}$. Pero en el capítulo siguiente, centrado en el acceso de Tarquinio al trono, utiliza el concepto de ambitio, siendo ésta la primera vez que tal término figura en su obra ${ }^{56}$. La ambitio hay que entenderla, dentro de este contexto, en un sentido político, el afán por obtener el poder solicitando los votos ${ }^{57}$, siendo Tarquinio Prisco, al decir de Livio, quien introdujo en Roma tal costumbre electoral. Este monarca se define entonces, según la expresión de E. Burck, como el primer homo ambitiosus de la historia de Roma ${ }^{58}$. La decisión de Livio de otorgar a Tarquinio esta innovación descansa sin duda en la sensación de que entonces tiene lugar una cesura en la evolución de la monarquía romana, iniciándose una nueva etapa. De hecho, el acceso al trono de los dos monarcas siguientes ya no se ajusta a las normas tradicionales, y el propio Livio no deja de señalar, en las respectivas historias de Servio Tulio y de Tarquinio el Soberbio, ciertas prácticas propias de la ambitio, si bien sin mencionar esta palabra ${ }^{59}$. En términos de interpretación histórica, puede decirse que a partir de Tarquinio Prisco comienza el proceso de degradación institucional de la monarquía, que culminará necesariamente con la instauración de la República.

Dionisio de Halicarnaso presenta los hechos de manera diferente. Según su relato, Tarquinio accede al poder en razón a sus propios méritos, y su entronización cumple además con todos los requisitos establecidos en el ritual de designación e investidura real ${ }^{60}$, quizá llevado por la voluntad de subrayar la continuidad entre las dos fases de la monarquía romana ${ }^{61}$. Además, Dionisio recoge una versión, desconocida por Livio y a la que el historiador de Halicarnaso prefiere no dar crédito, que muestra la ambitio de Anco por suceder a Tulo, hasta el punto de urdir una conspiración para asesinar al rey y ocupar el trono ${ }^{62}$. Por último, el mismo Dionisio parace trasladar a Servio la imagen de homo ambitiosus que Livio presta a Tarquinio, al presentarle como un hombre enérgico que incluso antes de ser nombrado regente, no quiere desaprovechar la ocasión para alcanzar el poder en contra de los derechos de sus pupilos ${ }^{63}$.

17 Además de la caracterización de los personajes, habría que preguntarse si Livio plantea también en su relato una perspectiva biográfica, y la respuesta no es sencilla. Como se sabe, salvo las vidas de Rómulo y Numa que redactó Plutarco, no conocemos biografías antiguas sobre los reyes de Roma, excepción hecha de los capítulos iniciales del De viris illustribus, que por su brevedad no tienen mayor contenido que un resumen del texto analístico. Por otra parte, el tono general de las Vidas de Plutarco pretende más resaltar las virtudes del protagonista que no ofrecer un relato detallado de sus hechos ${ }^{64}$. Pero en cualquier caso, tampoco se disponía entonces de datos suficientes para intentar una exposición minuciosa sobre la vida de los reyes, exceptuando quizá la de Rómulo, cuya leyenda se había enriquecido considerablemente a lo largo de los siglos. Sin embargo, Rómulo representa un caso excepcional, ya que es el fundador y por tanto objeto de mayor atención, y así se comprueba en toda la analística republicana. 
18 No obstante, no deja de tener interés una comparación entre la biografía de Numa redactada por Plutarco y los capítulos correspondientes del libro I de Livio. Una vez discutida la cronología de Numa a través de la leyenda de la relación del rey con Pitágoras, Plutarco menciona el origen de nuestro personaje -la ciudad de Cures-, el nombre de su padre, su fecha de nacimiento, su matrimonio con Tatia, su formación filosófica y la impronta que ésta marcó en su carácter; a continuación detalla la edad de acceso al trono -40 años-, los argumentos que esgrime Numa para rechazar la realeza y cómo al final, presionado por su padre y su amigo Marcio, acepta la propuesta del Senado. Numa se somete a la votación popular y busca la conformidad divina mediante la inauguratio. El grueso del relato está dedicado a las reformas religiosas cumplidas por el rey, con no escasos comentarios relativos a la doctrina pitagórica. Por último, Plutarco se refiere a la descendencia, con diversas variantes en la tradición, y el linaje que en época republicana se decía surgido de Numa.

19 Si acudimos ahora al texto de Livio, las diferencias son notables, sobre todo por omisión. Livio se limita a señalar la ciudad de Cures como lugar de procedencia de Numa; critica su supuesta relación con Pitágoras; le atribuye la institución de la inauguratio como parte de la ceremonia de investidura real, y finalmente refiere algunas de las innovaciones del rey en ámbito religioso. Nada dice sobre la ascendencia de Numa, ni sobre su rechazo inicial a asumir la realeza, y tampoco nada acerca de su descendencia. Este silencio de Livio es premeditado, ya que tales datos figuraban en la tradición analística. Así lo demuestra el relato de Dionisio, quien coincide con Plutarco en algunos datos concretos de la vida de Numa: así, el nombre de su padre, Pompilio Pompón ${ }^{65}$; la edad de acceso al trono, cuarenta años, considerada por los griegos la mejor época de la vida del hombre $(a c m e ́){ }^{66}$; su resistencia a aceptar el poder ${ }^{67}$, y por último su descendencia, mencionando las dos versiones existentes al respecto ${ }^{68}$.

A tenor de este ejemplo, parece entonces que Livio no tiene el propósito de incluir en su relato detalles concretos sobre la vida de los reyes, a no ser que estos sirvan al interés general de la exposición histórica. Así parece suceder en lo que se refiere a las relaciones familiares. Respecto a Rómulo, Livio se encuadra en la tradición canónica, si bien expresa ciertas dudas sobre la participación de Marte $^{69}$; además menciona a Hersilia como esposa de Rómulo ${ }^{70}$. Sobre Tulo dice Livio que era nieto de Hosto Hostilio, quien se había destacado junto a Rómulo en la batalla sobre el Foro contra los sabinos ${ }^{71}$. Esta indicación familiar no tiene otro fin que vincular el ardor guerrero de Tulo, su ferocitas, con la fama de su abuelo. La parquedad de Livio contrasta con el desarrollo que Dionisio ofrece sobre la ascendencia de Tulo: su abuelo procedía de Medullia, se unió en matrimonio con la noble sabina Hersilia (en otras versiones, la mencionada esposa de Rómulo), combatió con el fundador y fue enterrado, como premio a su valor, en el lugar más importante del Foro ${ }^{72}$.

21 La misma actitud se repite a propósito de Anco, de quien Livio dice que era nieto de Numa por vía materna ${ }^{73}$. Debe notarse que Livio sí menciona al padre de Anco, pero sin especificar tal parentesco: se trata de Numa Marcio, hijo de Marco, nombrado pontifex maximus por el rey Numa Pompilio ${ }^{74}$. En cualquier caso, este parentesco sirve para justificar la especial inclinación de Anco, siguiendo la estela de su abuelo, hacia la regularización de la doctrina sagrada, plasmada, según el relato de Livio, en la compilación del derecho pontifical y la institución de los rituales relativos a la guerra. No muy distante es el planteamiento inicial de Dionisio ${ }^{75}$. La diferencia entre ambos es que el historiador de Halicarnaso, no en este lugar sino al final de su relato sobre Numa, 
sí hace referencia al vínculo parental entre ambos monarcas detallando, a tenor de cuanto dice el analista $\mathrm{Cn}$. Gellio, que Numa tuvo una sola hija de la que nació Anco ${ }^{76}$. Pero uno y otro silencian toda noticia sobre la ascendencia paterna del rey, lo que por el contrario sí se encuentra en Plutarco ${ }^{77}$. Respecto a la descendencia de Anco, Livio menciona a sus hijos en diversas ocasiones, pero siempre en plural y sin especificar sus nombres $^{78}$. Su presencia se explica en primer lugar en función del fin violento de Tarquinio Prisco, y tan sólo muy secundariamente como elemento de la biografía de Anco.

Con la llegada de los Tarquinios las perspectivas cambian. Por vez primera en la historia de Roma se materializa una sucesión dinástica, protagonizada por la gens Tarquinia, con la presencia intermedia de Servio Tulio, a quien se hizo necesario incluir en el esquema genealógico de la familia real. Los personajes que conforman el stemma de los Tarquinios definen un conjunto muy numeroso, sin parangón respecto a la etapa histórica anterior, espaciándose a lo largo de más de un siglo ${ }^{79}$. Pero aun así, Livio se muestra más parco en proporcionar nombres, limitándose a aquellos que resultan necesarios a los fines de su exposición.

Sobre Tarquinio Prisco recuerda Livio sus antecedentes familiares, es decir su padre Demarato, su hermano Arrunte, su esposa Tanaquil y su sobrino póstumo Egerio ${ }^{80}$, personajes fundamentales casi todos ellos para comprender las vicisitudes del protagonista antes de su asentamiento en Roma. La presencia de Egerio se explica por ser el fundador de la rama Collatina de los Tarquinios, ya que el rey le encomendó el gobierno de la ciudad de Collatia y fue padre de L. Tarquinio Collatino ${ }^{81}$, uno de los impulsores del movimiento que acabó con la monarquía en Roma. En cuanto a la descendencia, Livio menciona cuatro hijos, pero de manera aislada, cuando el argumento de la exposición se lo exige: dos hijos, Lucio y Arrunte, y dos hijas, la primera casada con Servio Tulio y calificada simplemente como "hija de Tarquinio", y la segunda, llamada por su nombre, Tarquinia, es la madre de L. Junio Bruto e identificada como "hermana del rey", es decir Tarquinio el Soberbio ${ }^{82}$. Sobre esta relación familiar existía una doble versión, ya que una variante en la tradición les consideraba nietos, y no hijos de Tarquinio Prisco. La actitud de Livio al respecto es muy significativa sobre la concisión y escasa preocupación con la cual se expresa al tratar sobre tales cuestiones ${ }^{83}$. Es a propósito de Lucio, el futuro Tarquinio el Soberbio, cuando Livio recuerda estas diferencias, inclinándose por una de las versiones sin apenas argumentar su decisión ${ }^{84}$. El hecho contrasta con Dionisio de Halicarnaso, quien dedica al problema amplio espacio, con una discusión minuciosa, y se decanta finalmente, siguiendo al analista L. Calpurnio Pisón, por considerarles nietos ${ }^{85}$.

También el origen de Servio Tulio fue objeto de atención por parte de Livio, y en realidad no podía ser de otra manera. Como veíamos con anterioridad, Servio representa el punto culminante de la época monárquica y su acceso al trono, al decir del propio Livio, no se produjo de forma regular, de acuerdo con la costumbre, lo cual no le impide ser considerado como el último monarca justo y legítimo ${ }^{86}$. Livio parece conocer las diferentes versiones acerca del origen de Servio, pero de hecho sólo menciona aquélla que más le convence, en definitiva la que otorga al rey una ascendencia más noble, alejando cualquier insinuación sobre su supuesta esclavitud: Servio sería hijo de un princeps Corniculanus y de una mujer noble (cuyo nombre no menciona), a la cual la reina Tanaquil privó de la servidumbre acogiéndola en el palacio, donde, ya encinta, dió a luz un hijo ${ }^{87}$. Aquí se produce de nuevo un fuerte 
contraste con el relato paralelo de Dionisio, mucho más prolijo en detalles y que considera las diversas variantes, incluida aquella sobre la maravillosa concepción de Servio a partir del fuego del hogar ${ }^{88}$. Livio menciona asimismo su matrimonio con una hija de Tarquinio Prisco, como acabamos de ver, y el de sus hijas con los dos hijos de su antecesor ${ }^{89}$, con el fin de que no le ocurriese lo mismo que a Tarquinio con los hijos de Anco, aunque a la larga fue la causa última de su ruina.

Finalmente, Livio menciona los tres hijos de Tarquinio el Soberbio, Arrunte, Tito y Sexto. Este último, tenido por Livio como el menor ${ }^{90}$, es el que interpreta un papel más destacado, ya que su padre le encargó apoderarse de Gabii, donde encontró la muerte al tiempo que Tarquinio partía al exilio, y fue protagonista de uno de los episodios más drámaticos de toda la obra de Livio, la violación de Lucrecia. Arrunte y Tito aparecen como los enviados a Delfos por el rey para obtener respuesta sobre los prodigios que habían sucedido en el palacio ${ }^{91}$, y posteriormente intervienen en los acontecimientos bélicos urdidos por Tarquinio para recuperar el trono, Arrunte en la batalla de la silva Arsia $^{92}$ y Tito quizás en la del lago Regillo, ya que la identificación de ese filius Tarquinii no es muy clara ${ }^{93}$.

Otros elementos biográficos se encuentran en la descripción de los hechos de los reyes antes de alcanzar el trono. En este aspecto, el texto de Livio tampoco ofrece abundantes noticias. De hecho, si se exceptúa a Rómulo, cuya gesta prefundacional sí es relatada con cierto detalle como preámbulo necesario a su principal logro, la fundación de Roma, tan sólo en los capítulos correspondientes a los tres últimos reyes es posible observar algunos datos de carácter biográfico.

La historia previa de Tarquinio Prisco está condensada en un capítulo ${ }^{94}$. Reseña Livio el origen familar del rey, su fortuna al ser declarado heredero universal de los bienes de su padre y cómo sintiéndose incómodo en su natal Tarquinia, y empujado por su esposa, decidió trasladarse a Roma. A continuación Livio se detiene en el episodio sucedido en el Janículo con el prodigio del águila, pues en definitiva aquí radica su predestinación a la realeza, anunciada por el ave de Júpiter. Ya en Roma, Lucumo adopta el nombre de L. Tarquinio Prisco (!), utiliza interesadamente su riqueza y logra la amistad del rey Anco, quien le convierte en su consejero y le nombra tutor de sus hijos. En todo este relato destaca la ambición de su protagonista, como antes veíamos, pero que en no poca medida se justifica por vía divina a través del mencionado prodigio.

Más parco se muestra Livio al tratar sobre Servio, cuya vida anterior a la ocupación del trono transcurre en el palacio: tan sólo merecen ser reseñados el prodigio de la aureola de fuego, con el cual Servio aparece predestinado a la realeza, y su educación en el entorno real, que culmina con su matrimonio con la hija de Tarquinio ${ }^{95}$. De nuevo resulta interesante comparar los respectivos textos de Livio y de Dionisio. Si sobre Tarquinio Prisco ambos coinciden en líneas generales, con mayor desarrollo literario por parte del historiador griego, las diferencias se acusan más al considerar a Servio. Dionisio dedica un capítulo entero a reseñar las hazañas de Servio durante el reinado de su predecesor, con el objetivo de justificar su designación al trono ${ }^{96}$. Esta diferencia tiene su importancia, ya que refleja la distinta imagen sobre Servio que ofrecen estos autores: Livio sigue la versión aristocrática sobre Servio, y por tanto sustenta su realeza proporcionándole connotaciones heroicas; Dionisio, por el contrario, se alinea en la tendencia que veía en Servio a un rex popularis, por lo que su elevación al trono no deja de ser consecuencia de sus propios méritos. 

parte importante del libro I, los doce últimos capítulos (49-60) -aunque en realidad ya comienza a ocupar un primer plano en la narración a partir del capítulo 46-, en suma una extensión sólo comparable a la dedicada a Rómulo. Sin embargo, la información histórica que proporciona es muy escasa en relación a la amplitud del relato. Esto es así porque toda la exposición de Livio está en función de resaltar la maldad y perversidad de Tarquinio y su familia, especialmente su esposa Tulia y su hijo Sexto. Así sucede con los dos hechos históricos que más desarrolla, la imposición de la hegemonía romana sobre los latinos y la incorporación de la ciudad de Gabii. En ambos episodios, Livio destaca, por encima de cualquier otra consideración, las males artes que Tarquinio -y en el caso de Gabii también Sexto- utiliza para obtener sus objetivos, de manera que el fin justifica los medios, al margen de toda moralidad. Por el contrario, Dionisio no deja de atribuir la institución de las feriae Latinae a Tarquinio como aspecto relevante de su hegemonía en el Lacio, sea o no cierta la noticia, y de igual manera cuando este rey impuso el foedus Gabinum, Dionisio afirma que cumplió con las ceremonias y juramentos pertinentes, y sobre la piel del buey sacrificado hizo escribir los términos del acuerdo, depositando el documento en el templo de Dius Fidius ${ }^{97}$. Esta actitud religiosamente correcta de Tarquinio no interesa a Livio.

Como se sabe, el relato de nuestro historiador acerca del último rey de Roma aparece envuelto entre dos tragedias, la primera sobre los crímenes que culminan con el asesinato de Servio y la entronización del propio Tarquinio, la segunda centrada en la violación de Lucrecia, iniquidad que desencadena el proceso que conducirá al establecimiento de la libertas ${ }^{98}$. Esta concepción trágica del devenir histórico constituye un impedimento a la hora de transmitir datos propiamente históricos, ya que el interés se dirige hacia el análisis moral del carácter y comportamiento de los protagonistas. En definitiva, pocos elementos biográficos pueden obtenerse en el relato de Livio sobre Tarquinio el Soberbio.

31 A la vista de lo expuesto, es posible obtener dos conclusiones generales. Por una lado, Livio no desprecia el retrato, como decía al comienzo de estas páginas. Pero los retratos sobre los reyes no representan tipos generales de antiguos romanos, personajes abstractos que simbolizan una o varias de las virtudes tenidas por características del hombre romano. Cierto es que los reyes pueden representar un concepto, pero éste se adapta a las condiciones históricas transmitidas por la tradición, aunque en ocasiones tamizadas por la propia época de Livio reflejada en el pasado. Por ejemplo, la ambitio de Tarquinio Prisco recuerda la actitud electoral de los políticos republicanos; la moderatio de Servio Tulio hay que entenderla como el establecimiento de un equilibrio entre las clases según el modelo "ciceroniano", como señala B. Mineo", que en el caso concreto de Servio se expresa con la introducción de un discrimen, a tenor de la fortuna, considerado como natural; la superbia del último rey no representa sino una monarquía degradada y corrupta, preámbulo necesario de la República.

En cuanto a la intención biográfica, no puede afirmarse que estuviese entre las primeras preocupaciones de Livio. Como veíamos previamente, Livio sólo introduce elementos biográficos cuando se lo exige el argumento de la narración. Por ello, de hecho sólo se extiende relativamente en los casos de Rómulo y de Tarquinio Prisco, lo cual está perfectamente justificado desde el punto de vista histórico, ya que el primero es el fundador y el segundo aquél que inaugura una nueva época. Naturalmente la falta de información fiable, propio para una época tan lejana, impide profundizar en la vida 
de los personajes, pero aun así, la confrontación con Dionisio, que en la práctica dispone del mismo material que Livio, deja ver con claridad que este último silencia intencionadamente, quizás por la brevedad de su relato, nombres y hechos que sí eran conocidos. Se podría pensar también que el protagonista del relato es el pueblo romano, representado por sus monarcas, pero en realidad no es así. Son los reyes quienes asumen todas las iniciativas y se convierten en autores de la historia. En suma, se podría concluir con la expresión que F. Chamoux aplica a cómo Diodoro relata la historia de Filipo de Macedonia, "biographie en action", en el sentido que los hombres son caracterizados por sus hechos ${ }^{100}$.

\section{BIBLIOGRAFÍA}

AMPOLO C. 1983, «La storiografia su Roma arcaica e i documenti», en Tria corda: Scritti inonore di A. Momigliano, Biblioteca di Athenaeum 1, Como, p. 9-26.

BELLANDI A. 1976, «Scelus Tulliae. Storiografia e tipologia tragica in Dionigi, Livio, Ovidio», PP 31, p. $148-168$.

BERNARD J.-E. 2000, Le portrait chez Tite-Live : essai sur une écriture de l'histoire romaine, Coll.

Latomus 253, Paris.

BESSONE L. 1982, «La gente Tarquinia», RFIC 110, p. 394-415.

BRIQUEL D. 1998, «Tarquins de Rome et idéologie indo-européenne (II). Les vicissitudes d'une dynastie», Revue d'histoire des religions 215, 4, p. 419-450.

BRUNO L. 1966, «Crimen regni e superbia in Tito Livio», GIF 19, p. 236-259.

BURCK E. 1934, Die Erzählungskunst des T. Livius, Problemata. Forschungen zur klassischen Philologie 11, Berlin.

BURCK E. 1992, Das Geschichtswerk des Titus Livius, Bibliothek der klassischen Altertumswissenschaften. 2. Reihe 87, Heidelberg.

CAZANOVE O. de 1988, «La chronologie des Bacchiades et celle des rois étrusques de Rome», MEFRA 100, p. 615-648.

CHAMoux F. 1997, «La biographie dans la Bibliothèque historique de Diodore de Sicile», en J.A. Sánchez Marín, J. Lens Tuero, C. López Rodríguez (eds), Historiografía y biografía: actas del coloquio internacional sobre historiografía y biografía (de la Antigüedad al Renacimiento), Granada, 21-23 septiembre de 1992, Musae Ibericae neolatinae, Madrid, p. 57-65.

DUNKLE J.R. 1967, «The Greek Tyrant and Roman Political Invective of the Late Republic», TAPhA 98, p. 151-171.

DUNKLE J.R. 1971, «The Rhetorical Tyrant in Roman Historiography: Sallust, Livy and Tacitus», CW 65 , p. $12-20$.

ERNST E. 1969, «Zwei pisonische Varianten bei Livius?», Hermes 97, p. 126-127.

FELDHERR A. 1998, Spectacle and Society in Livy's History, Berkeley - Los Angeles - London. 
FOX M. 1996, Roman Historical Myths: The Regal Period in Augustan Literature, Oxford Classical Monograph, Oxford.

FROMENTIN V. 2002, «Servius Tullius sans Fortuna? ou la figure du roi Servius Tullius chez Denys d'Halicarnasse», en M. Fartzoff, É. Smadja, É. Geny (eds), Pouvoir des hommes, signes des dieux dans le monde antique, Besançon, p. 53-77.

GABBA E. 1969, «Il "Brutus” di Accio», Dionisio 43, p. 377-383.

GANTZ T.N. 1975, «The Tarquin Dynasty», Historia 24, p. 539-554.

GIACCHERO M. 1973, Storiografia romana antica, Genova.

HELLEGOUARC'H J. 1972, Le vocabulaire latin des relations et des partis politiques sous la République, $2^{\mathrm{e}}$ éd. revue et corrigée, Coll. d'études anciennes, Paris.

HOOKER E.M. 1963, «The Significance of Numa's religious Reforms», Numen 10, 2, p. 87-132.

KONSTAN D. 1986, «Narrative and Ideology in Livy: Book I», ClAnt 5, p. 198-215.

KÖVES-ZULAUF T. 1982-1984, «Die Herrschaftsdauer der römischen Könige», AAntHung 30, p. 191-203.

MARTIN P.M. 1976, «Le souci chronologique dans la tradition sur la généalogie des Tarquins», en R. Chevalier (ed.), Aiôn : le temps chez les Romains, Caesarodunum bis 10, Paris, p. 55-64.

MARTIN P.M. 1982, L'idée de royauté à Rome. I, De la Rome royale au consensus républicain, Miroir des civilisations antiques 1 , Clermont-Ferrand.

MARTÍNEZ-PINNA J. 1985, «La reforma de Numa y la formación de Roma», Gerión 3, p. 97-124.

MARTíNEZ-PINNA J. 1989, «La tradición sobre el origen de Tarquinio Prisco», en Atti II Congresso Internazionale Etrusco, I, Suppl. di Studi Etruschi, Roma, p. 129-145.

MARTÍNEZ-PINNA J. 1996, «In convivio Luxuque: mujer, moralidad y sociedad en el mundo etrusco», Brocar 20, p. 31-56.

MARTÍNEZ-PINNA J. 2011, «Diodoro Sículo y los reyes de Roma», Gerión 29, 1, p. 107-121 <http:// dx.doi.org/10.5209/rev_GERI.2011.v29.n1.39047>.

MÉNAGER L.-R. 1976, «Les collèges sacerdotaux, les tribus et la formation primordiale de Rome», MEFRA 88, p. 455-543.

MENSCHLING E. 1966, «Tullus Hostilius, Alba Longa und Cluilius. Zu Livius I 22 f. und anderen», Philologus 110, p. 102-118.

MICHELS A.K. 1951, «The Drama of the Tarquins», Latomus 10, p. 13-24.

MINEO B. 2006, Tite-Live et l'histoire de Rome, Études et commentaires 107, Paris.

MOLES J. 1993, «Livy's Preface», PCPhS 39, p. 141-168.

OGILVIE R.M. 1965, A Commentary on Livy Books 1-5, Oxford.

OPPERMANN H. 1967, «Die Einleitung zum Geschichtswerk des Livius», en E. Burck (ed.), Wege zu Livius, Wege der Forschung 132, Darmstadt, p. 169-180.

PENELLA R.J. 1990, «Vires/robur/opes in Livy's Account of Romulus and Tullus Hostilius», CQ 40, p. 207-213.

PENELLA R.J. 2004, «The Ambitio of Livy's Tarquinius Priscus», CQ 54, 2, p. 630-635. 
PHILLIPS J.E. 1979, «Livy and the Beginning of a New Society», CB 55, p. 87-92.

SÁNCHEZ MARÍN J.A., LENS TUERO J., LÓPEZ RODRÍGUEZ C. (eds) 1997, Historiografía y biografía: actas del coloquio internacional sobre historiografía y biografía (de la Antigüedad al Renacimiento), Granada, 21-23 septiembre de 1992, Musae Ibericae neolatinae, Madrid.

SAUTEL J.-H. 1999, «L'autorité dans la Rome royale selon Denys d'Halicarnasse. Aperçus sémantiques», RBPh 77, p. 77-104.

SCHOLZ U.W. 1997, «Annales et historia(e)», en Historia y biografía, Madrid, p. 79-90.

SEITA M. 2000, «Una tragedia senza palcoscenico: Tarquinio il Superbo e i suoi familiari secondo Tito-Livio», BStudLat 30, p. 485-513.

STEELE R.B. 1904, «The Historical Attitude of Livy», AJPh 25, p. 15-44.

TAINE H. 1856, Essai sur Tite Live, Paris.

THOMSEN R. 1980, King Servius Tullius: A Historical Synthesis, Humanitas 5, Copenhagen.

VERBRUGGHE G. 1989, «On the Meaning of Annales, on the Meaning of Annalist», Philologus 133, p. $192-230$.

WALSH P.G. 1955, «Livy's Preface and the Distorsion of History», AJPh 76, p. 369-383.

WALSH P.G. 1961, Livy: His Historical Aims and Methods, Cambridge.

WISEMAN T.P. 1983, «The Wife and the Children of Romulus», CQ 33, 2, p. 445-452.

ZANCAN P. 1940, Tito Livio: Saggio storico, Milano.

\section{NOTAS}

*. Este artículo se enmarca en el proyecto de investigación HUM2005-01590, del Ministerio de Educación y Ciencia, y en el grupo de investigación HUM-696, financiado por la Junta de Andalucía.

1. Recuérdese, por ejemplo, la controversia entre los analistas Cn. Gellio y Licinio Macer a propósito de cuándo tuvo lugar la llegada de Tarquinio Prisco a Roma: Dion., 4.6.4.

2. Véanse Scholz 1997; Verbrugghe 1989.

3. Cf. Ogilvie 1965, p. 30: «The structure of the book is dictated by the length and character of the reigns of the kings».

4. Liv., Praef., 9. Walsh 1955, p. 370.

5. Cf. Giacchero 1973, pp. 330 ss.

6. Corn. Nep., Pelop., 1.1.

7. Véase Oppermann 1967, pp. 172 ss.

8. Taine 1856, p. 186.

9. Bernard 2000, pp. 42 ss.

10. Bernard 2000, p. 30. Así también Walsh 1961, p. 85.

11. Cf. sin embargo las dudas expresadas en 1.4.2.

12. Liv., 1.15.6-8.

13. Liv., $1.39 .4 ; 1.48 .8-9$.

14. Numa: Liv., 1.21.6; Tulo: Liv., 1.31.8; Anco: Liv., 1.35.1.

15. Cf. Mineo 2006, p. 180.

16. Liv., 1.18.1-4. Sobre una posible derivación de este pasaje del analista L. Calpurnio Pisón, Ernst 1969. 
17. Liv., 1.22.2. Véase Penella 1990.

18. Liv., 1.22.3-7; siguen esta tendencia Flor., 1.3.2; Dion Casio (Zon., 7.6); Oros., 2.4.9; Serv., Aen., 6.813. Una visión más favorable a Tulo se encuentra en Cic., Rep., 2.17.31; Dion., 3.2-3; Diod., 8.25-26. Sobre la cuestión, Menschling 1966.

19. Liv., 1.28.11.

20. Liv., 1.31.6.

21. Liv., 1.26.8.

22. Permítaseme remitir a Martínez-Pinna 2011, con bibliografía previa.

23. Liv., 1.32.4.

24. Liv., 1.35.4-6.

25. Liv., 1.60.3 (cronología); 2.21.5 (muerte).

26. Liv., 1.46.4-5.

27. Liv., 1.53.1.

28. Liv., 1.46.6.

29. Cf. Walsh 1961, p. 76.

30. Liv., 1.57.9.

31. Sobre el significado de la expresión de Livio, permítaseme remitir a mi trabajo MartínezPinna 1996, pp. 35 s.

32. Burck 1992, p. 133.

33. Bernard 2000, pp. 197 ss.

34. Cf. Köves-Zulauf 1982-1984, pp. 197 s.

35. Pueden verse al respecto, Hooker 1963; Ménager 1976, pp. 456 ss.; Martínez-Pinna 1985.

36. La única empresa militar que la tradición atribuye a Servio se concluye con una victoria sobre una coalición etrusca (Liv., 1.42.2-3; Dion., 4.27), y su historicidad suscita además serias dudas: Thomsen 1980, pp. 288 ss.; Martin 1982, pp. 159 ss.

37. Cf. Cic., Rep., 2.25.45, donde Servio es llamado optimus rex.

38. Liv., 2.1.2.

39. Liv., 1.48.8.

40. Liv., 1.4.1.6. Según Dionisio, el procedimiento de elección de Servio fue justamente al contrario, es decir reinó con la aprobación del pueblo pero sin el consentimiento del Senado (Dion., 4.12.3), diferencia que se explica por las diferentes tendencias de la tradición acerca de Servio, aristocrática la primera, popular la segunda.

41. Liv., 1.48.9. De forma similar se expresa Dionisio (4.40.3), quien sin embargo utiliza el término, más radical, de demokratía.

42. Liv., 1.60.4.

43. Véase Dunkle 1971, pp. $12 \mathrm{~s}$.

44. Accio, fr. 40 R (= Cic., Pro Sest., 58.123).

45. Cf. Gabba 1969.

46. Dunkle 1971, pp. 13 ss.; del mismo autor, puede verse asimismo Dunkle 1967.

47. Zancan 1940, p. 27.

48. Véase Bruno 1966, pp. 236 ss.

49. Liv., 1.17.3.

50. Phillips 1979; Fox 1996, pp. 97 s.

51. Según el mismo Livio (2.1.2), la superbia del último rey propició la instauración de la República.En similar sentido se expresa Floro en su recapitulación sobre la etapa monárquica de la historia de Roma (1.8). En su opinión, el carácter de cada uno de los reyes fue de utilidad para la época que les correspondió vivir: así, Rómulo es calificado como ardens, Numa como religiosus, Tulo como bellator y Anco como aedificator; Tarquinio Prisco es resaltado por haber introducido los ornamenta et insignia y Servio el census; finalmente del último Tarquinio destaca su superbia, que trajo consigo la cupiditas libertatis. 
52. Walsh 1961, p. 93; Ogilvie 1965, p. 30.

53. Cf. Konstan 1986, pp. 202 ss.

54. Liv., 1.34.5.

55. Liv., $1.6 .4 ; 17.1$.

56. Liv., 1.35.2.

57. Cf. sobre este término en el lenguaje político, Hellegouarc'h 1972, pp. 208 ss.

58. Burck 1934, p. 158; esta idea de que la ambitio llega a Roma, según Livio, con Tarquinio Prisco es también defendida por Moles 1993, pp. 155 s. Sobre el particular, véase Penella 2004.

59. Cf. Penella 2004, p. 633. La progresiva degradación en la forma de acceso al poder de los últimos reyes según el relato de Livio es resaltada por Fox 1996, pp. 118 ss.

60. Dion., 3.46.1.

61. Cf. Sautel 1999, p. 89.

62. Dion., 3.35.2-6.

63. Dion., 4.4.1; en similar sentido, Zon., 7.9. Cf. Fromentin 2002, pp. 63 s.

64. Cf. Plut., Alex., 1.2: «Pues yo no escribo historias, sino vidas».

65. Dion., 2.58.2; Plut., Num., 3.6.

66. Dion., 2.58.2; Plut., Num., 5.1.

67. Dion., 2.60.1; Plut., Num., 5-6.

68. Dion., 2.76.5; Plut., Num., 21.1-6.

69. Liv., 1.4.2.

70. Liv., 1.11.2. Véase Plut., Rom., 14.7-8, donde figuran diversas versiones acerca de este personaje. Sobre el particular, Wiseman 1983.

71. Liv., 1.22.1. Las hazañas de Hostio son relatadas por Livio en 1.12.2-3.

72. Dion., 3.1.2. Sobre la "tumba" de Hostilio, Ampolo 1983, pp. 19 ss.

73. Liv., 1.32.1.

74. Liv., 1.20.5. Plutarco, por su parte, menciona una tradición en la que el abuelo de Anco compitió con Tulo por suceder a Numa, causándole la derrota una profunda desesperación (Plut., Num., 21.5).

75. Dion., 3.16.2-4.

76. Dion., 2.76.5; Gellio, fr. 17 Peter $=$ fr. 17 Chassignet.

77. Plut., Num., 21.5-6.

78. Liv., 1.34.2: Tarquinio Prisco, tutor de los hijos de Anco; 1.35.1-2: rivalidad con Tarquinio por obtener el trono; 1.40: complot para asesinar al rey; 1.41.7: exilio en Suessa Pometia tras el triunfo de Servio; 1.42.1: animadversión hacia Tarquinio Prisco.

79. Pueden verse, con diferentes planteamientos, Gantz 1975; Martin 1976; Bessone 1982.

80. Liv., 1.34.1-4. Sobre las diferentes tradiciones, Martínez-Pinna 1989.

81. Liv., 138.1; 57.5 .

82. Liv., $1.39 .4 ; 56.7$.

83. Steele 1904, p. 18: «When the annalists disagree, Livy is usually content to leave the question undecided, and it would have been futile for him to attempt to restore lost facts».

84. Liv., 1.46.4. Aunque no lo dice, Livio sigue aquí a Fabio Píctor: fr. $11 \mathrm{P}=$ fr. $12 \mathrm{a}$ Ch (= Dion., 4.6.1).

85. Dion., 4.6-7. Piso, fr. $15 \mathrm{P}=17 \mathrm{Ch}$. Es conocida la escasa confianza que Pisón le merece a Livio y la preferencia por Fabio, como se observa asimismo a propósito del botín obtenido en Pometia y dedicado por Tarquinio el Soberbio a la consturcción del gran tamplo de Júpiter: Liv., 1.55.8. Cf. Steele 1904, p. 28. Sobre la cuestión del vínculo parental entre ambos Tarquinios reyes, Martin 1976, p. 59; Bessone 1982, pp. 394 ss.; Cazanove 1988, pp. 616 ss.

86. Liv., 1.48.8.

87. Liv., 1.39.5. Cf. sin embargo las palabras que el mismo Livio pone en boca del tribuno Canuleyo acerca del origen de Servio (4.3.12). 
88. Dion., 4.1-2.

89. Liv., 1.42.1.

90. Liv., 1.53.1. Esta misma condición se la presta Ovidio (Fast., 2.691), mientras que para Dionisio (3.55.1) y Cicerón (Rep., 2.25.46) Sexto era el mayor.

91. Liv., 1.56.7.

92. Liv., 2.6.6-9.

93. Liv., 2.19-20. Sobre este asunto deben consultarse Martin 1976, p. 60 ss.; Bessone 1982, pp. 408 ss.

94. Liv., 1.34 .

95. Liv., 1.39.1-4.

96. Dion., 4.3.

97. Dion., 4.49.2, y 58.4, respectivamente.

98. Según Michels 1951, la historia de la casa de los Tarquinios es presentada en Livio en tres secciones, correspondientes a otros tantos supuestos dramas dominados por mujeres, Tanaquil, Tulia y Lucrecia. La existencia del primero de ellos sucita sin embargo bastantes dudas. Sobre el tema hay una amplísima bibliografía, de la que a modo de ejemplo se pueden citar además: Bellandi 1976; Briquel 1998, pp. 435 ss.; Seita 2000, con referencias previas. Buenas observaciones en Feldherr 1998, pp. 187 ss.

99. Mineo 2006, pp. 189 ss.

100. Chamoux 1997, p. 62. Véase asimismo Walsh 1961, p. 83.

\section{RESÚMENES}

Pour la description de l'époque royale, l'unité narratologique est le règne de chacun des rois. Le livre I de Tite-Live est en fait une succession de biographies, genre qui est censé privilégier moins les faits qu'un portrait moral. Peu ou prou, les rois illustrent tous, avec un dosage propre, cinq caractéristiques fondamentales : ils sont des rois légitimes et justes, des tyrans, des guerriers, des religieux, des bâtisseurs. Seul Tarquin le Superbe reste en marge de cette typologie : lui n'est que tyran, condensé de toutes les connotations négatives de la monarchie. La comparaison des portraits liviens avec ceux que proposent Plutarque, Denys ou Diodore montre que Tite-Live n'a nulle intention de retenir tous les détails biographiques. Le cas est frappant avec Tarquin le Superbe; bien que le portrait occupe les douze derniers chapitres, l'information historique donnée est faible, en comparaison avec Denys, beaucoup plus objectif, alors que Tite-Live dresse un portrait tragique. Avec les rois, Tite-Live ne renonce pas au portrait, mais ne leur donne pas la qualité de types généraux de vertus romaines qu'on voit dans les livres postérieurs. Et les éléments biographiques n'y interviennent qu'en appui d'un argumentaire : c'est une biographie en action. 
ÍNDICE

nomsmotscles Accius (Lucius), Cneius Gellius, Denys d'Halicarnasse, Diodore de Sicile, Florus, Nepos (Cornelius), Orose, Plutarque, Tite-Live

Índice geográfico: Cumes, Gabies, Janicule, Lac Régille

Mots-clés: historiographie antique, idéologie, portrait, royauté à Rome

Keywords: ancient historiography, ideology, portrait, Roman kingship

\section{AUTORES}

JORGE MARTÍNEZ-PINNA

Universidad de Málaga 